\title{
Another word on parsing relative clauses: Eyetracking evidence from Spanish and English
}

\author{
MANUEL CARREIRAS \\ Universidad de La Laguna, Tenerife, Spain \\ and \\ CHARLES CLIFTON, JR. \\ University of Massachusetts, Amherst, Massachusetts
}

\begin{abstract}
Ambiguity as to what the relative clause modifies in phrases such as Someone shot the maid of the actress who was divorced/Alguien disparó contra la criada de la actriz que estaba divorciada tends to be resolved differently in different languages (and in different forms of complex noun phrases). In English, there is a weak but seldom significant tendency for the relative clause to be taken as modifying the second noun phrase, the actress, but in Spanish, several researchers have found a significant preference for the relative clause's modifying the first noun phrase, la criada. The present experiments compare Spanish and English readers' eye movements while reading exactly comparable sentences in their native languages and find a significant reading time advantage in Spanish when it is forced to modify the first noun phrase, but in English when the relative clause is forced to modify the second noun phrase. Theoretical implications of the findings for previous explanations of the phenomenon are discussed.
\end{abstract}

Sentence comprehension involves more than simply retrieving word meanings. It also requires an analysis of constituent structure - that is, an analysis of the relative ordering of words in the sentence and of the grammatical roles played by these words. In order to figure out "who did what to whom," we need to be able to identify the who, the whom, and the what in the internal structure of the sentence-the argument structure of the sentence (see MacDonald, Pearlmutter, \& Seidenberg, 1994a, 1994b; Pritchett, 1992). One of the primary goals of recent psycholinguistic research has been to specify the psychological processes underlying how readers and listeners decide on the argument structure of sentences. This research has made it clear that language users rely on their knowledge of the grammar of their language in interpreting sentences (see Frazier, 1983, for a discussion).

In addition to determining the argument structure of sentences, language comprehension requires identifying any phrases that modify the role players and event or state described by the sentence. We need to figure out the when, the where, and the why of the sentence, and we need

\footnotetext{
This research was supported by Grants DGES-PB96-1048 from the Spanish Ministry of Education and HD-18708 from the NIH. We are grateful to Enrique Meseguer, Moises Betencourt, Nayantara Santhi, Jill Lohmeier, and Antonia Gaffran for their help with data collection. We also thank Don Mitchell, Morton Gernsbacher, and an anonymous reviewer for their helpful criticisms on an earlier draft of this manuscript. Correspondence concerning this article should be addressed either to M. Carreiras, Departamento de Psicologia Cognitiva, Universidad de La Laguna, 38205, Tenerife, Spain (e-mail: manuel.carreiras (a)ull.es) or to C. Clifton, Department of Psychology, University of Massachusetts, Amherst, MA 01003 (e-mail: cec@psych.umass.edu).
}

to determine the referents of the phrases that fill the argument roles and to determine what properties are being attributed to these referents. Frazier and Clifton (1996) present some evidence to support their claim that what they call primary versus nonprimary phrases (a contrast that subsumes the argument/adjunct contrast) are processed following quite different principles. The answers researchers have obtained to questions about how arguments are parsed may or may not fully apply to questions about how nonarguments are parsed.

Experimental research aimed at investigating how readers and listeners coordinate syntactic and nonsyntactic information has examined such structures as the main clause/relative clause (RC) ambiguity (1), the noun phrase (NP)/sentence complement ambiguity (2), the prepositional phrase attachment ambiguity (3), and the adverb attachment ambiguity (4); Frazier, 1979; Frazier \& Rayner, 1982; cf. Frazier \& Clifton, 1996). All of these, except (4), involve ambiguities of argument structure, ambiguities of "who did what to whom." Descriptively, readers and listeners seem to prefer to assign a simpler structure to a phrase and to attach a phrase to a recent constituent. From an autonomous syntax perspective, these preferences have been taken to reflect the parsing strategies of minimal attachment and late closure (Frazier, 1979; Frazier \& Rayner, 1982), but they can be interpreted from an interactive perspective as reflecting frequency of experience, salience, or referential simplicity (Crain \& Steedman, 1985; MacDonald et al., 1994a, 1994b; Trueswell \& Tanenhaus 1994).

$1 \mathrm{a}$. The horse raced past the barn and fell.

b. The horse raced past the barn fell. 
2 a. John knew the answer very well.

b. John knew the answer was wrong.

$3 \mathrm{a}$. The policeman shot the man with the gun.

b. The policeman shot the man with the binoculars.

4 a. Bill said that John will come tomorrow.

b. Bill said that John will come yesterday.

Defenders of an autonomous syntactic processor claim that we show a consistent preference, in the face of syntactic ambiguity, for the most simple interpretation. Thus, the minimal attachment strategy (Frazier, 1979, 1987)do not postulate any potentially unnecessary nodes-ensures that the simplest and, therefore, the most quickly derived analysis is adopted initially. Further, the late closure strategy-if grammatically permissible, attach new items into the clause or phrase currently being processed ensures that the new constituents are immediately assembled with the nearby constituents, minimizing the chances of short-term memory overload.

If minimal attachment and late closure are general strategies for parsing that are based on cognitive principles, they should apply universally, in all constructions and all languages. However, Cuetos and Mitchell (1988) presented evidence against the universality of late closure by showing that it fails to apply in Spanish to the parsing of RCs preceded by complex NPs. The construction examined by Cuetos and Mitchell is of particular interest because it involves an ambiguity of a nonargument, a nominal modifier. How such a construction is processed could shed some light on the possibility of differences between parsing arguments and parsing nonarguments and, potentially, could constrain the applicability of principles such as late closure.

Cuetos and Mitchell (1988) showed that Spanish readers, when faced with sentences like (5)-

$5 \mathrm{a}$. Someone shot the female servant of the actress who was on the balcony.

b. Alguien disparó contra el criado de la actriz que estaba en el balcón.

-instead of attaching the RC (who was on the balcony) to the $\mathrm{N} 2$ of the complex NP (N1 of N2), as would be predicted by the late closure strategy, prefer to take the N1 (el criado) as the host of the RC.

This ambiguous structure, involving a complex NP followed by an RC, is of particular interest, inasmuch as it is resolved differently in different languages. In Spanish, French, German, and Dutch, the head of the complex NP (N1) is preferred as subject of the RC (Brysbaert \& Mitchell, 1996b; Carreiras, 1992; Carreiras \& Clifton, 1993; Cuetos \& Mitchell, 1988; Cuetos, Mitchell, \& Corley, 1996; Gilboy, Sopena, Clifton, \& Frazier, 1995; Hemforth, Konieczny, \& Scheepers, 1994; Mitchell, Cuetos, \& Zagar, 1990; Zagar, Pynte, \& Rativeau, 1997). Italian readers apparently initially prefer N2 as the agent (DeVincenzi \& Job, 1993, 1995; but cf. the criticism of Pynte \& Frenck-Mestre, 1996, suggesting that those effects could be contaminated by the composition of the experimental lists). In English, the data are mixed; both an N2 preference in questionnaires (Cuetos \& Mitchell, 1988) and, recently, with eyetracking measures (Henstra, 1996) and a lack of preference (Carreiras \& Clifton, 1993) have been reported.

Focusing our attention on the case of English and Spanish, the experimental evidence shows a preference for a high attachment of the $\mathrm{RC}$ to the $\mathrm{Nl}$, whereas in English there is no preference (Carreiras \& Clifton, 1993) or a bias to the N2 (Henstra, 1996). However, quite recently, Gilboy and Sopena (1996) questioned the often replicated evidence of high attachment preference for the $\mathrm{RC}$ to the N1 in Spanish by arguing that the results reflected the effects of how the materials in the self-paced reading experiments that have been conducted in Spanish were segmented. In particular, they presented subjects with sentences, such as those used in Carreiras and Clifton (1993), using two different types of segmentation. One, called large segmentation (6), includes the complex NP as a whole and has been used in the majority of reported experiments. The other type, small segmentation (7), splits the complex NP into two displays and was used by De Vincenzi and Job (1995) to demonstrate an initial N2 preference in Italian. ${ }^{1}$

6 a. La policía arrestó a la hermana del criado/que dio a luz recientemente a dos gemelos.

b. The police arrested the sister of the handyman/ who recently gave birth to twins.

7a. La policía arrestó/a la hermana/del criado/que dio a luz recientemente a dos gemelos.

b. The police arrested/the sister/of the handyman/ who recently gave birth to twins.

Gilboy and Sopena obtained the usual effect of an on-line preference for high attachment of the RC to the $\mathrm{N} 1$ only with the large segmentation (6). No effects were found with the small one (7). They concluded that the N1 preference effect arises only when a particular type of segmentation that allows characteristics of prosodic patterns in Spanish to appear is used. However, when prosody is not allowed to come into play, as occurs with the small segmentation, the effects do not show up. Thus, such results challenge the previous ones by implying that high attachment is not a general preference in Spanish for this type of ambiguity, but an experimental artifact, a by-product of the segmentation of materials.

The question examined here has two parts: (1) whether the often observed N1 preference in Spanish is a byproduct of segmentation through the implicit assignment of prosodic pauses or an underlying property of Spanish and (2) whether native English readers and native Spanish readers would resolve the ambiguity of attachment of an RC preceded by a complex NP in different ways, when faced with sentences that are literal translations between the two languages. In order to capture any subtle on-line reading time effects, as well as to overcome 
Table 1

Sample Sentences Used in Experiment 1 (Spanish) and in Experiment 3 (English)
N1 host (high attachment)
El policia salió temprano de la comisaría y arrestó a la hermana del criado que dió a luz
recientemente a dos gemelos en el hospital.
The police came from headquarters early this morning and arrested the sister of the
handyman who recently gave birth to twins in the hospital.
N2 host (low attachment)
El policia salió temprano de la comisaria y arrestó al hermano de la niñera que dió a luz
recientemente a dos gemelos en el hospital.
The police came from headquarters early this morning and arrested the brother of the
nursemaid who recently gave birth to twins in the hospital.
Note-The boldface word was the critical disambiguating region.

any bias of the segmentation of the materials, eye movements were recorded. It has been argued that eyetracking during reading is an unobtrusive measure that avoids problems of the segmentation of materials, as it occurs with other self-paced methods, and is more sensitive to initial syntactic processing than are other response measures (Rayner, Sereno, Morris, Schmauder, \& Clifton, 1989). In three eye movement studies, conducted in Spanish (Experiments 1 and 2) and in English (Experiment 3), we examined Spanish and English readers' performances for ambiguous structures of the type $\mathrm{N} 1$ of $\mathrm{N} 2 \mathrm{RC}$, to determine their initial attachment preferences.

\section{EXPERIMENT 1}

This experiment had two goals. The first goal was to replicate and extend, with a more refined technique (the recording of eye movements), previous results that showed a high attachment preference, obtained in Spanish using self-paced reading methods (e.g., Carreiras, 1992, Carreiras \& Clifton, 1993; Cuetos \& Mitchell, 1988). This is important, because Gilboy and Sopena (1996) argued that such effects could be an experimental artifact restricted to the particular type of segmentation used in those studies. The second goal was to allow a comparison of data obtained with native Spanish readers with another set of data produced by native English readers, using the same apparatus and equivalent materials in both cases.

\section{Method}

Subjects. The subjects were 44 undergraduate students at the University of La Laguna, who participated in the experiment for course credit.

Apparatus. The sentences were presented in lowercase letters on a video screen interfaced with a PC-compatible computer. The monitor displayed up to 80 characters per line, and the sentences were displayed in two lines. The subjects were seated $73 \mathrm{~cm}$ from the monitor, and 3 characters equaled $1^{\circ}$ of visual angle.

The subjects' eye movements were monitored by a Fourward Technologies Dual Purkinje Eyetracker (Generation 5) that was interfaced to the computer. The eyetracker has a resolution of $10 \mathrm{~min}$ of arc (better than half a character). Viewing was binocular, with eye position recorded from the right eye. The signal from the eyetracker was sampled every millisecond by the computer.
Materials and Design. Parallel English and Spanish versions of the 16 sentences used in Carreiras and Clifton's (1993) Experiments 1-4, which contained a complex NP (N1 de N2) followed by an RC, were adapted for eyetracking purposes. ${ }^{2}$ The changes consisted of adding some extra information at the beginning and at the end of the sentences, so that the complex NP and the RC always appeared on the same line on the screen. An example appears in Table 1.

The RC attachment to either N1 (high attachment) or to N2 (low attachment) was disambiguated by gender information. In half of the sentences, the interpretation of the sentences was conceptually compatible only with a high attachment of the RC to the $\mathrm{N} 1$, and in the other half, only with a low attachment to the N2. In addition, the content of the RC required a feminine host for half the sentences and a masculine host for the other half. Disambiguation was accomplished by reversing the gender of the $\mathrm{N} 1$ and $\mathrm{N} 2$.

Procedure. When a subject arrived for the experiment, he or she was seated in front of the monitor with his or her head in a chinrest, to cancel head movements. The initial calibration of the eyetracking system generally required about $5 \mathrm{~min}$. The subject was asked to read sentences displayed on the monitor and told that he or she would be questioned about the sentences and should read for comprehension. Questions were asked on approximately one third of the trials. The subject was instructed to look at a fixation box, which outlined the first character position of the sentence, before reading each sentence. A red dot within the square indicated that the subject was correctly looking at the first square and was ready to start to read, and the experimenter pressed a button to display the sentence, causing a sentence to appear immediately on the screen. After reading the sentence, the subject pressed a button that could cause either the presentation of a question or the beginning of the next trial. When a question appeared on the screen, the subjects had to press one of two buttons to answer yes or no.

Each subject initially read 8 practice sentences, to become familiar with the procedure. Then he or she read the 16 experimental sentences, intermixed randomly with 144 other sentences that served as fillers to divert attention from the structure of the materials.

\section{Results and Discussion}

For the purpose of the analysis, the critical region was considered to be the first content word (plus a previous function word, if appropriate) that clearly disambiguated the $\mathrm{RC}$ toward a masculine or feminine host. Table 1 shows that the critical disambiguating region for that particular example consisted of the boldface words a luz. The fixation duration measures (first-pass time and total time) were divided by the number of characters in the region, to produce milliseconds per character. This procedure was done not to correct for any differences in the lengths 
Table 2

Means and Standard Deviations (SD) of the First-Pass and Total Reading Times in Milliseconds per Character for the Critical Region of the RC in the High (N1) and Low (N2) Attachment Conditions (Experiment 1)

\begin{tabular}{lrrrrr} 
& \multicolumn{2}{c}{ First Pass } & & \multicolumn{2}{c}{ Total Time } \\
\cline { 2 - 3 } \cline { 5 - 6 } Condition & $M$ & $S D$ & & $M$ & $S D$ \\
\hline High Attachment & & & & \\
$\quad$ Feminine & 41.0 & 13.4 & & 48.4 & 15.4 \\
$\quad$ Masculine & 40.8 & 9.3 & & 51.0 & 16.5 \\
$\quad$ Mean & 40.9 & 11.5 & & 49.7 & 15.8 \\
$\quad$ Low Attachment & & & & \\
$\quad$ Feminine & 42.0 & 13.3 & & 48.6 & 13.9 \\
$\quad$ Masculine & 42.8 & 12.2 & & 58.5 & 19.3 \\
$\quad$ Mean & 42.4 & 12.7 & 53.6 & 17.5 \\
\hline
\end{tabular}

of critical regions (since the critical regions were the same in the two experimental conditions; see Trueswell, Tanenhaus, \& Garnsey, 1994, for a discussion of the shortcomings of using milliseconds per character to correct for length), but simply to reduce error variance by making different items roughly comparable with each other in reading time. The per character reading times (first-pass and total reading times) for the critical region of the sentences are shown in Table 2.

Although first-pass times were numerically faster in the critical region when the sentences were disambiguated toward high attachment than when they were disambiguated toward low attachment, the differences did not approach significance in analyses of variance (ANOVAs) by subjects and by items $\left[F_{1}(1,43)=1.50, M S_{\mathrm{e}}=64.47\right.$, $\left.p>.05 ; F_{2}(1,14)=1.20, M S_{\mathrm{e}}=22.12, p>.05\right]$. In addition, no significant differences were found between masculine and feminine hosts $\left(F_{1}<1 ; F_{2}<1\right)$ and for the interaction between type of host and type of disambiguation $\left(F_{1}<1 ; F_{2}<1\right)$. However, the ANOVAs on the total reading times indicated that the subjects read the critical regions more rapidly when they disambiguated toward high attachment $(\mathrm{N} 1)$ than when they disambiguated toward low attachment $\left[\mathrm{N} 2 ; F_{1}(1,43)=5.87\right.$, $M S_{\mathrm{e}}=111.25, p<.05 ; F_{2}(1,14)=4.65, M S_{\mathrm{e}}=35.79$, $p<.05]$. In addition, sentences that required a feminine host for disambiguation were read faster than sentences with a masculine host, as indicated in the analysis by subjects $\left[F_{1}(1,43)=9.76, M S_{\mathrm{e}}=176.73, p<.01\right.$; $\left.F_{2}(1,14)=3.24, M S_{\mathrm{e}}=120.19, p<.1\right]$. The interaction was not reliable $\left[F_{1}(1,43)=3.49, M S_{\mathrm{e}}=170.63, p>.05\right.$; $\left.F_{2}(1,14)=2.19, M S_{\mathrm{e}}=35.79, p>.05\right]$.

The total time results suggest that high attachment preferences are real, not just a by-product of the segmentation of materials, as was suggested by Gilboy and Sopena (1996). Eyetracking during reading is an unobtrusive measure that allows presentation of the sentences as a whole (unsegmented) to the subjects. The present results thus provide additional experimental evidence consistent with previous findings of a high attachment preference in Spanish (Carreiras, 1992; Carreiras \& Clifton, 1993; Cuetos \& Mitchell, 1988).

\section{EXPERIMENT 2}

Although the interaction of gender and attachment was not significant in Experiment 1, the high attachment advantage was numerically present only when the disambiguating part of the $\mathrm{RC}$ required a masculine antecedent. This may be because more masculine than feminine RCs contained disambiguating morphology. Five of the eight masculine items were disambiguated morphologically as well as conceptually, but only one of the eight feminine items. Furthermore, the high attachment advantage observed in Experiment 1 was significant only in total times, although the same tendency was also observed in firstpass reading times. In order to avoid the problem of having different types of disambiguation for masculine and feminine hosts, as well as to be in a position to identify any earlier (first-pass) structural bias in favor of high attachment, in this second experiment, all the sentences were disambiguated by morphological (as well as conceptual) gender.

\section{Method}

Subjects. The subjects were 36 undergraduate students at the University of La Laguna, who participated in the experiment for course credit.

Apparatus and Procedure. The same apparatus and the same procedure as those of the previous experiment were used.

Materials and Design. The design was the same as that of the previous experiment. The 16 experimental sentences were rewritten in order to make all of them disambiguated by morphological (as well as conceptual) gender and to shorten them to a maximum of 80 characters, so they could fit on a single line (see Table 3 ). Twentysix filler sentences were also included.

\section{Results and Discussion}

The per character reading times for the critical region of the sentences are shown in Table 4. ANOVAs by subjects and by items carried out on the first-pass reading times did not show any significant effects of the type of disambiguation closure $\left[F_{1}(1,35)=1.89, M S_{\mathrm{e}}=63.53\right.$, $\left.p>.05 ; F_{2}<1\right]$, the type of host $\left(F_{1}<1, F_{2}<1\right)$, or the interaction $\left[F_{1}(1,35)=1.88, M S_{\mathrm{e}}=61.52, p>.05\right.$; $\left.F_{2}<1\right]$.

The ANOVAs on the total reading times showed once more that regions disambiguating toward high attachment (N1) were read faster than those disambiguating toward low attachment $\left[\mathrm{N} 2 ; F_{1}(1,35)=6.97, M S_{\mathrm{e}}=68.15\right.$, $\left.p<.05 ; F_{2}(1,14)=4.67, M S_{\mathrm{e}}=47.26, p<.05\right]$. In addition, sentences that required a feminine host for dis-

Table 3

Sample Sentences Used in Experiment 2 (Spanish)

N1 host (high attachment)

Alguien disparó contra la criada del actor que estaba divorciada

Someone shot the servant (f) of the actor who was divorced (f)

N2 host (low attachment)

Alguien disparó contra el criado de la actriz que estaba divorciada. Someone shot the servant $(m)$ of the actress who was divorced (f)

Note-The boldface word was the critical disambiguating region 
Table 4

Means and Standard Deviations (SD) of the First-Pass and Total Reading Times in Milliseconds per Character for the Critical Region of the RC in the High (N1) and Low (N2) Attachment Conditions (Experiment 2)

\begin{tabular}{lrrrrr}
\hline & \multicolumn{2}{c}{ First Pass } & & \multicolumn{2}{c}{ Total Time } \\
\cline { 2 - 3 } \cline { 5 - 6 }$M$ & & & & $M$ & $S D$ \\
\hline High Attachment & & & & & \\
Feminine & 28.1 & 9.2 & & 33.6 & 12.4 \\
Masculine & 29.8 & 10.4 & & 38.0 & 13.3 \\
Mean & 29.0 & 9.8 & & 35.8 & 12.9 \\
Low Attachment & & & & \\
Feminine & 31.7 & 12.4 & & 38.9 & 14.7 \\
Masculine & 29.8 & 10.3 & & 41.7 & 15.6 \\
Mean & 30.8 & 11.3 & 40.3 & 15.2 \\
\hline
\end{tabular}

ambiguation were read faster, as was indicated in the analysis by subjects $\left[F_{1}(1,35)=6.12, M S_{\mathrm{e}}=77.04, p<\right.$ $\left..05 ; F_{2}<1\right]$. The interaction was not reliable $\left(F_{1}<1\right.$, $F_{2}<1$ ).

These results show again a preference for high attachment in sentences of the type NP1 of NP2 RC. Thus, they replicate and extend the results already obtained in the previous experiment, as well as the ones obtained with self-paced reading methods. It is important to note that the effect is not restricted to a particular type of gender disambiguation. Now, attachment effects seem to be present for items disambiguated to the feminine as well as for those disambiguated to the masculine.

\section{EXPERIMENT 3}

The goal of the third experiment was to determine whether English readers do have a bias to initially interpret an RC as modifying the most recent noun, N2, in an on-line task, as they have sometimes been reported to have in off-line questionnaire studies. Several possible reasons for such an English-specific bias will be mentioned in the General Discussion section. However, Experiment 3 was not designed to distinguish among these possibilities. Its goal was simply to establish, more securely than has been done in the past, whether there is an on-line bias in English toward an N2 modification preference.

\section{Method}

Subjects. The subjects were 36 undergraduate students at the University of Massachusetts, who participated in the experiment for course credit.

Apparatus and Procedure. The same apparatus and the same procedure as those of the previous experiment were used, except that the subject's head was held steady by a bite bar, rather than by a chinrest.

Materials and Design. The materials and design were the same as those of Experiment 1, translated into American English (see Table 1), plus 96 fillers.

\section{Results and Discussion}

Table 5 shows the per character reading times for the critical region of the sentences. ANOVAs by subjects and by items were carried out on the first-pass reading times. They indicated that the subjects read the critical region more rapidly when it disambiguated toward low attachment (N2) than when it disambiguated toward high attachment $\left[\mathrm{N} 1 ; F_{1}(1,35)=4.86, M S_{\mathrm{e}}=81.06, p<.05\right.$; $\left.F_{2}(1,14)=4.94, M S_{\mathrm{e}}=10.99, p<.05\right]$. However, the other two effects, type of host $\left(F_{1}<1, F_{2}<1\right)$ and the interaction $\left[F_{1}<1 ; F_{2}(1,14)=3.02, M S_{\mathrm{e}}=10.99, p>\right.$ $.05]$, were not significant.

The ANOVAs on the total reading times again revealed differences for the critical region, showing that low attachment (N2) disambiguations were read faster than high attachment (N1) ones, although the difference was significant only by subjects $\left[F_{1}(1,35)=4.57, M S_{\mathrm{e}}=145.70\right.$, $\left.p<.05 ; F_{2}(1,14)=3.08, M S_{\mathrm{e}}=29.17, p<.10\right]$. No effect involving gender was significant in any analysis $\left(F_{1}<1, F_{2}<1\right)$, nor was the interaction $\left[F_{1}<1\right.$; $\left.F_{2}(1,14)=3.04, M S_{\mathrm{e}}=29.17, p>.05\right]$.

Experiment 3 established an overall N2 disambiguation advantage in English, significant both in first-pass and (marginally) in total reading times. Therefore, we believe that we can conclude that our English readers showed a measurable difficulty in reading an RC disambiguated toward an N1 interpretation, as compared with an N2 interpretation. We (Carreiras \& Clifton, 1993) previously reported a null effect of using a moving window methodology. However, Henstra (1996) obtained a low attachment advantage, using eyetracking methodology, as did we, which suggests that the real effect can be captured when a sensitive enough measure is used.

\section{GENERAL DISCUSSION}

The primary question addressed here is answered clearly: Spanish readers have a modest but measurable preference for interpreting an RC as modifying NPI in structures like NP1 de NP2 RC. This preference is not a consequence of segmentation, as was suggested by Gilboy and Sopena (1996), but appears in the reading of normal texts. Furthermore, the preference for high attachment is not simply an effect of using eyetracking methodology. American English readers show a comparable preference

Table 5

Means and Standard Deviations (SD) of the First-Pass and Total Reading Times in Milliseconds per Character for the Critical Region of the RC in the High (N1) and Low (N2) Attachment Conditions (Experiment 3)

\begin{tabular}{|c|c|c|c|c|}
\hline \multirow[b]{2}{*}{ Condition } & \multicolumn{2}{|c|}{ First Pass } & \multicolumn{2}{|c|}{ Total Time } \\
\hline & $M$ & $S D$ & $M$ & $S D$ \\
\hline \multicolumn{5}{|c|}{ High Attachment } \\
\hline Feminine & 38.8 & 10.6 & 46.8 & 16.5 \\
\hline Masculine & 39.1 & 9.2 & 46.1 & 15.2 \\
\hline Mean & 38.9 & 9.9 & 46.5 & 15.9 \\
\hline \multicolumn{5}{|c|}{ Low Attachment } \\
\hline Feminine & 34.7 & 7.6 & 40.2 & 12.3 \\
\hline Masculine & 36.6 & 9.5 & 44.1 & 12.2 \\
\hline Mean & 35.7 & 8.7 & 42.2 & 12.4 \\
\hline
\end{tabular}


for low attachment of an RC. Such a result has generally not been found in self-paced reading experiments in English, but a low attachment preference has sometimes been reported in eyetracking experiments (Henstra, 1996). It has not always been found, however (Traxler, Pickering, \& Clifton, 1998).

Although the pattern of data supports a high attachment preference in Spanish and a low attachment preference in English, there are some aspects of the data that deserve comment. First, in Experiment 1, the attachment effect was limited to RCs that require a masculine head. However, the attachment effect appeared for both types of items in Experiment 2, where morphological disambiguation was always used. Furthermore, a replication of Experiment 1, carried out with 39 subjects reading the same sentences embedded in a total of 122 items, showed a total time high attachment advantage for both masculine and feminine items (significant, however, only by subjects, not by items, owing to one sharply deviant item).

Second, in the English experiment, the low attachment advantage was significant in first-pass times, whereas the high attachment advantage in Spanish was significant only in total times. However, each of the Spanish experiments showed a tendency toward favoring high attachment in first-pass reading times, and this tendency was significant by subjects (not by items) when Experiment 1 was pooled with its replication $\left[F_{1}(1,81)=3.98, M S_{\mathrm{e}}=61.70, p<.05\right]$. The mean of high attachment in milliseconds per character was 40.5 , whereas that for low attachment was 42.2 .

We suspect that there is an across-the-board advantage for high attachment in Spanish and for low attachment in English, considering complex NPs such as those used here. This difference will, presumably, not appear in all the versions of complex NPs studied by Gilboy et al. (1995) and certainly not in other types of phrases, such as those studied by Igoa, Carreiras, \& Meseguer (1998). The advantages show up quickly, but not strongly enough to appear always in first-pass times. However, we do not think that any substantive conclusions can be drawn from the different patterns of significance in first-pass and total times. We suspect that the occasional nonsignificance of our effects simply reflected a lack of experimental power. We certainly do not want to claim that significant firstpass effects reflect only the influence of structural information (as Zagar et al., 1997, apparently assume). Many experiments have found that first-pass times reflect nonsyntactic information (e.g., Garnsey, Pearlmutter, Myers, \& Lotocky, 1997; Speer \& Clifton, 1998; Traxler \& Pickering, 1996; Trueswell et al., 1994). Whether disruption appears in early measures, such as first-pass time, or only in later total time measures seems to depend on when disambiguating information becomes available to the reader. When disambiguating information is available quickly and its implications for resolving an ambiguity are clear enough, it will affect early measures of reading.

The present research demonstrates a substantial difference between Spanish and English readers in their preferences for the interpretation of some complex NPs. The difference does not simply reflect some method- ological artifact (cf. Gilboy \& Sopena, 1996), but presumably reflects something about the normal processing of the two languages. The present demonstration of a difference, however, only opens for further study the question of why the languages differ. It does not resolve the question. Several alternatives have been proposed. Some are inadequate. Spanish does not generally violate late closure. Cuetos and Mitchell (1988) recognized this, noting that their experimental demonstration of the failure of late closure in Spanish RCs relied on the operation of late closure (or some comparable principle favoring low attachment) to effect the disambiguation. As was discussed by Fodor (1998), this admission allows low attachment to be viewed as the expression of a universal processing principle such as late closure, overridden by other factors in certain constructions of certain languages (cf. Frazier, 1990, and Frazier \& Clifton, 1996, for further discussion; cf. Igoa et al., 1998, for an experimental demonstration of late closure in other Spanish constructions). Other suggestions for why languages differ in their RC attachment preferences have uncertain support at best. For example, the tuning hypothesis (Mitchell \& Cuetos, 1991), which asserts that the initial resolution of all structural ambiguities will be determined by the frequencies with which alternative disambiguations have been previously encountered, received support from a smallscale corpus analysis of English and Spanish (Cuetos, Mitchell, \& Corley, 1996). However, inconsistencies between data from subjects' responses (off and on line) and from corpus analysis have been reported for English (Gibson, Schütze, \& Salomon, 1996; see also Gibson, Pearlmutter, Canseco-Gonzalez, \& Hickok, 1996) and Dutch (Brysbaert \& Mitchell, 1996b, 1996b; Mitchell \& Brysbaert, 1998). The predicate-proximity and recency hypotheses (Gibson, Pearlmutter, et al., 1996; Gibson, Schütze, \& Salomon, 1996) posit that the initial preferences are guided by the relative weights of two parameters with opposite forces: predicate proximity (attach to the head of the predicate) and recency (attach to the most recent site). Presumably, the relative weights of these parameters differ among languages. However, the reason for such variation is not clear. If the variation is assumed to depend on the frequency with which different constructions are experienced, this hypothesis may fall victim to the problems that beset the tuning hypothesis.

Following a different approach, Frazier and Clifton (1996) argued that the existence of the Saxon genitive (e.g., the colonel's daughter who was on the porch) in English was the basis of the difference. As was discussed earlier, they limit late closure to primary phrases (and later, in Frazier \& Clifton, 1998, suggest that late closure may not be an independent processing principle, but simply a reflection of visibility, which amounts to the availability of a phrase in memory for initial analysis, reanalysis, and interpretation). In the case of modifiers (one kind of nonprimary phrase), they propose a discourse-based acrossthe-board preference for high attachment. This general preference is counteracted in English by the availability of the Saxon genitive. Gricean logic suggests that if a 
speaker had wanted to express high attachment, he or she would have used the 's form; since he or she did not, low attachment was probably intended. However, Dutch has a Saxon genitive, yet shows a high attachment preference (Brysbaert \& Mitchell, 1996b). Since the Dutch Saxon genitive is very limited in use, the implications of this fact are not yet clear, but it at least complicates the hypothesis.

One further hypothesis is that of Hemforth, Konieczny, and Scheepers (in press), who claim that RCs in German and other languages are interpreted much like pronouns. They are associated by default with the most salient available host, which will generally be N1, the head of the complex NP and commonly an argument of the main predicate of the sentence. However, English may differ from other languages studied, because the word commonly used to introduce an RC is the complementizer that, not a relative pronoun. This may cause English relative clauses to be treated less like pronouns and more like complement phrases, obeying late closure. This suggestion, unfortunately, does not explain why DeVincenzi and Job (1995) obtained a late closure preference in Italian, which consistently uses a relative pronoun. A final hypothesis is that advanced by Fodor (1998), who proposes that there is a cross-language preference to attach phrases as sisters to phrases of about the same size (probably, phonological or syntactic size). Since RCs are generally somewhat heavy, they prefer a relatively large host phrase. High attachment makes the entire $N 1$ of $N 2$ phrase the host, closer in size to a typical relative clause than is the $N 2$ phrase. In English, Fodor speculates that, since the complementizer that (or even a relative pronoun plus the copula, who was) is typically phonologically reduced, it may be absorbed into the preceding prosodic phrase. This makes English $N 2$ relatively heavier and the relative clause correspondingly less heavy, encouraging their attachment as sisters.

\section{REFERENCES}

BrysbaerT, M., \& Mitchell, D. C. (1996a, June). Modifier attachment in Dutch: Deciding between garden-path, construal and statistical tuning accounts of parsing. Paper presented at the workshop on Computational Models of Human Syntactic Processing, Netherlands Institute for Advanced Studies, Wassenaar.

BrysbaerT, M., \& MitchelL, D. C. (1996b). Modifier attachment in sentence processing: Evidence from Dutch. Quarterly Journal of Experimental Psychology, 49A, 664-695.

Carreiras, M. (1992). Estrategias de análisis sintáctico en el procesamiento de frases: Cierre temprano versus cierre último [Strategies for syntatic analysis in sentence processing: Early closure vs. late closure]. Cognitiva, 4, 3-27.

Carreiras, M., \& Cufton, C. (1993). Relative clause interpretation preferences in Spanish and English. Language \& Speech, 36, 353372.

Crain, S., \& Steedman, M. (1985). On not being led up the garden path: The use of context by the psychological syntax processor. In D. R. Dowty, L. Kartunnen, \& A. M. Zwicky (Eds.), Natural language parsing: Psychological, computational, and theoretical perspectives (pp. 320-358). Cambridge: Cambridge University Press.

Cuetos, F., \& Mitchell, D. C. (1988). Cross-linguistic differences in parsing: Restrictions on the use of the late closure strategy in Spanish. Cognition, 30, 73-105.

Cuetos, F., Mitchell, D. C., \& Corley, M. M. B. (1996). Parsing in different languages. In M. Carreiras, J. E. García-Albea, \& N. Sebastián (Eds.), Language processing in Spanish (pp. 145-187). Hillsdale, NJ: Erlbaum.

DE VINCENZI, M., \& JoB, R. (1993). Some observations on the universality of the late closure strategy: Evidence from Italian. Journal of Psycholinguistic Research, 22, 189-206.

DE VINCENZI, M., \& JoB, R. (1995). An investigation of late closure: The role of syntax, thematic structure, and pragmatics in initial and final interpretation. Journal of Experimental Psychology: Learning, Memory, \& Cognition, 21, 1-19.

FoDoR, J. (1998). Learning to parse? Journal of Psycholinguistic Research, 27, 285-319.

FrazIER, L. (1979). On comprehending sentences: Syntactic parsing strategies. Bloomington: Indiana University Linguistics Club.

Frazier, L. (1983). Processing sentence structure. In K. Rayner (Ed.), Eye movements in reading: Perceptual and language processes (pp. 215236). New York: Academic Press.

Frazier, L. (1987). Sentence processing: A tutorial review. In M. Coltheart (Ed.), Attention and performance XII: The psychology of reading (pp. 559-586). Hillsdale, NJ: Erlbaum.

Frazier, L. (1990). Parsing modifiers: Special purpose routines in the human sentence processing mechanism? In D. A. Balota, G. B. Flores d'Arcais, \& K. Rayner (Eds.), Comprehension processes in reading (pp. 303-330). Hillsdale, NJ: Erlbaum.

Frazier, L., \& Clifton, C., Jr. (1996). Construal. Cambridge, MA: MIT Press.

Frazier, L., \& Clifton, C., JR. (1998). Sentence reanalysis and visibility. In J. D. Fodor \& F. Ferreira (Eds.), Sentence reanalysis (pp. 143-176). Dordrecht: Kluwer.

FraZIER, L., \& RAYNER, K. (1982). Making and correcting errors during sentence comprehension: Eye movements in the analysis of structurally ambiguous sentences. Cognitive Psychology, 14, 178-210.

Garnsey, S. M., Pearlmutter, N. J., Myers, E., \& Lotocky, M. A. (1997). The contributions of verb bias and plausibility to the comprehension of temporarily ambiguous sentences. Journal of Memory \& Language, 37, 58-93.

Gibson, E., Pearlmutter, N., Canseco-Gonzalez, E., \& Hickok, G (1996). Cross-linguistic attachment preferences: Evidence from English and Spanish. Cognition, 59, 23-59.

Gibson, E., Schürze, C. T., \& Salomon, A. (1996). The relationship between the frequency and the complexity of linguistic structure Journal of Psycholinguistic Research, 25, 59-92.

Gilboy, E., \& Sopena, J.-M. (1996). Segmentation effects in the processing of complex noun pronouns with relative clauses. In M. Carreiras, J. E. Garcia-Albea, \& N. Sebastián (Eds.), Language processing in Spanish (pp. 191-206). Hillsdale, NJ: Erlbaum.

Gilboy, E., Sopena, J.-M., Clifton, C., Jr., \& Frazier, L. (1995). Argument structure and association preferences in Spanish and English compound NPs. Cognition, 54, 131-167.

Hemforth, B., Konieczny, L., \& Scheepers, C. (1994). Principlebased or probabilistic approaches to human sentence processing. In B. Hemforth, L. Konieczny, C. Scheepers, \& G. Strube (Eds.), First analysis, reanalysis and repair (IIG-Berichte $8 / 94$; pp. 79-90). AlbertLudwigs Universität, Freiburg.

Hemforth, B., KonieCzNy, L., \& ScheePERs, C. (in press). Syntactic attachment and anaphor resolution: The two sides of relative clause attachment. In M. Crocker, M. Pickering, \& J. C. Clifton (Eds.), Architecture and mechanisms of language processing. Cambridge: Cambridge University Press.

HENSTRA, J. (1996, September). Relative clause attachment in English: Eye-tracking versus self-paced reading. Poster presented at Architecture and Mechanisms of Language Processing-96, Turin, Italy.

Igoa, J. M., Carreiras, M., \& Meseguer, E. (1998). A study on late closure in Spanish: Principle-grounded vs. frequency-based accounts of attachment preferences. Quarterly Journal of Experimental Psychology, 51A, 561-592.

MacDonald, M. C., Pearlmutter, N., \& Seidenderg, M. S. (1994a). The lexical nature of syntactic ambiguity resolution. Psychological Review, 101, 676-703.

MacDonald, M. C., Pearlmutter, N., \& Seidenberg, M. S. (1994b). Syntactic ambiguity resolution as lexical ambiguity resolution. In 
C. Clifton, L. Frazier, \& K. Rayner (Eds.), Perspectives on sentence processing (pp. 123-153). Hillsdale, NJ: Erlbaum.

Mitchell, D. C., \& Brysbaert, M. (1998). Challenges to recent theories of language differences in parsing: Evidence from Dutch. In D. Hillert (Ed.), Sentence processing: A cross-linguistic perspective (pp. 313-355). New York: Academic Press

Mitchell, D. C., \& Cuetos, F. (1991). The origins of parsing strategies. In C. Smith (Ed.), Current issues in natural language processing (pp. 1-12). Austin: University of Texas, Center for Cognititive Science.

Mitchell, D. C., Cuetos, F., \& Zagar, D. (1990). Reading in different languages: Is there a universal mechanism for parsing sentences? In D. A. Balota, G. B. Flores d'Arcais, \& K. Rayner (Eds.), Comprehension processes in reading (pp. 285-302). Hillsdale, NJ: Erlbaum.

PritcheTt, B. L. (1992). Grammatical competence and parsing performance. Chicago: University of Chicago Press.

Pynte, J., \& Frenck-Mestre, C. (1996, September). Evidence for early-closure attachments on first-pass reading times in French: A replication. Poster presented at Architecture and Mechanisms of Language Processing-96, Turin, Italy.

Rayner, K., Sereno, S. C., Morris, R. K., Schmauder, A. R., \& Clifton, C., Jr. (1989). Eye movement and on-line language comprehension processes. Language \& Cognitive Processes, 4, 21 -49.

SPEer, S., \& Clifton, C., JR. (1998). Plausibility and argument structure in sentence comprehension. Memory \& Cognition, 26, 965-978.

Traxler, M. J., \& Pickering, M. J. (1996). Plausibility and the processing of unbounded dependencies: An eye-tracking study. Journal of Memory \& Language, 35, 454-475.
Traxler, M. J., Pickering, M. J., \& Clifton, C., JR. (1998). Adjunct attachment is not a form of lexical ambiguity resolution. Journal of Memory \& Language, 39, 558-592.

Trueswell, J. C., \& Tanenhaus, M. K. (1994). Toward a constraintbased lexicalist approach to syntactic ambiguity resolution. In C. Clifton, L. Frazier, \& K. Rayner (Eds.), Perspectives on sentence processing (pp. 155-179). Hillsdale, NJ: Erlbaum.

Trueswell, J. C., Tanenhaus, M. K., \& Garnsey, S. M. (1994). Semantic influences on parsing: Use of thematic role information in syntactic ambiguity resolution. Journal of Memory \& Language, 33, 285-318.

Zagar, D., Pynte, J., \& Rativeau, S. (1997). Evidence for early closure attachment on first-pass reading times in French. Quarterly Journal of Experimental Psychology, 50A, 421-438.

\section{NOTES}

1. DeVincenzi and Job (1995) also succeed in showing an initial N2 preference in Italian, using a large segmentation, so the segmentation used cannot be the only reason for the DeVincenzi and Job (1995) results.

2. The materials are available from either of the authors by e-mail (manuel.carreiras@ull.es or cec@psych.umass.edu) or from the Web page (http://www.umass.edu/ cec).

(Manuscript received April 28, 1998; revision accepted for publication October 21,1998 .) 